\title{
ТОЛЕРАНТНОСТЬ СТУДЕНТОВ РОССИЙСКИХ УНИВЕРСИТЕТОВ КАК УСЛОВИЕ СУЩЕСТВОВАНИЯ И ОТЧУЖДЕНИЯ ЛИЧНОСТИ В МУЛЬТИКУЛЬТУРНОМ МИРЕ
}

\author{
Скаковская Наталия Вячеславовна1, \\ pnv@tpu.ru \\ Вторушин Николай Анатольевич1, \\ notabene1977@yandex.ru \\ Погукаева Анна Вячеславовна², \\ annapogukaeva1@rambler.ru \\ ${ }^{1}$ Национальный исследовательский Томский политехнический университет, \\ Россия, 634050, г. Томск, пр. Ленина, 30 \\ 2 Российский университет дружбы народов, \\ Россия, 117198, г. Москва, ул. Миклухо-Маклая, 6
}

\begin{abstract}
Скаковская Наталия Вячеславовна, кандидат философских наук, доцент отделения социальногуманитарных наук Школы базовой инженерной подготовки Национального исследовательского Томского политехнического университета.
\end{abstract}

Вторушин Николай Анатольевич, старший преподаватель отделения социально-гуманитарных наук Школы базовой инженерной подготовки Национального исследовательского Томского политехнического университета.

Погукаева Анна Вячеславовна, старший преподаватель кафедры № 2 Факультета русского языка и общеобразовательных дисциплин Российского университета дружбы народов.

Сформулирована проблема сущности толерантности, которая связана, с одной стороны, со ставшей привычной идеей демократии и философией либерализма, а с другой стороны - с новой культурной и политической реальностями. Представлено понимание взаимоотношения культурного и религиозного контекстов толерантности. Осмыслены результаты исследования студенческой адаптации в контексте толерантности. Актуальность обусловлена трансформаций образования, отражающаяся в тенденциях интернационализации, компьютеризации и интеграции образовательных систем разных стран. Цель: оценить возможности и преимущества толерантного поведения в образовательной среде. Методы. Основу исследования составляет социокультурный подход, раскрывающий тенденции современного образования. С помощью философской рефлексии отражены новые аспекты толерантности в духовном опыте человека. Социологические методы позволили проанализировать понимание толерантного поведения студентов. Результаты. Даны философские оценки того, как мы можем наилучшим образом быть толерантными в самых разных культурных обществах, опираясь на универсальные моральные ценности и образование. Авторы представляют проблему толерантности в новом аспекте - как источник отчуждения личности в многочисленных культурных связях. Представлены выводы исследования толерантного поведения студентов Томского политехнического университета и Российского университета дружбы народов: роль религиозных, культурных, традиционных, гендерных, семейных аспектов в толерантной коммуникации. Показано, почему проблема толерантности в российских вузах не стоит так же остро, как в европейских. Выделены образовательные компетенции современного толерантного студента: умение избегать конфликтных ситуаций, понимание и принятие других культур и российского социума, навыки преодоление социально-психологических барьеров, умения и навыки ведения «диалога культур» с помощью изучения языка. Сформулированы образовательные компетенции современного толерантного студента: умение избегать конфликтных ситуаций, понимание и 
принятие других культур и российского общества, преодоление социально-психологического барьера, формирование навыков и умений вести «диалог культур».

Ключевые слова: Толерантность, высшее образование, мультикультурализм, адаптация студентов, отчуждение.

Для понимания проблемного контекста заявленной темы обратимся к либерализму, провозгласившему права и индивидуальные свободы человека. Сквозь ключевые идеи либерализма, на наш взгляд, возможно наиболее точно раскрыть ключевые черты проблемы толерантности, мотивации толерантного поведения и взаимоотношений культурного и религиозного контекстов толерантности.

Философские традиции либерализма считают толерантность ключевым компонентом либерального политического порядка общества.

Когда субъекты общества достаточно терпимы, политические разногласия могут быть решены миролюбиво, однако существует риск возникновения несогласий из-за различных систем политических ценностей. Хотя исторически уже много сделано для актуализации ценности толерантности, выработаны образцы поведения социальных классов, более и менее толерантных. Но мало что сделано в современном глобальном мире для воспитания мотивации индивидуального толерантного поведения. Во всех ли ситуациях субъект поведет себя толерантно? С одной стороны, быть толерантным тебя обязывает общество, с другой стороны, толерантность - это часть моральных норм.

Многие ситуации, происходящие сегодня в мире, иллюстрируют избирательную толерантность или взрыв интолерантности после долгой терпимости [1]. Есть основания полагать, что эту ситуацию, которая сосредоточена на наших моральных обязанностях по отношению друг к другу, трудно поддерживать, особенно перед лицом всё более многообразного населения. Миграционные кризисы современного мира меняют понятие толерантности. Гуманитарная ситуация, изменение социокультурного пространства, десятилетиями внедряемая концепция толерантности и прав человека, и при этом новая европейская и российская реальности транслирует совершенно иные «вызовы современности» [2].

Авторы статьи стремятся понять, как мы можем наилучшим образом содействовать терпимости в самых разных обществах, опираясь на универсальные моральные ценности и образование.

\section{Сущность толерантности}

В самом общем виде толерантность подразумевает некоторую терпимость субъекта по отношению к другому, контроль негативных эмоций, вмешательства и неприятие. Так, толерантность может пониматься как акт принятия того, что вы не одобряете [3].

Субъект поставлен в ситуацию выбора в разных социальных условиях: политика, бизнес, университетская среда, религия, социальные сети и даже медицина.

Дж. Хортон [3] представляет толерантные действия как конфликты причин, некоторые из которых побуждают человека не одобрять другого и мешать его действиям, а некоторые - воздерживаться от вмешательства, несмотря на его первоначальное неодобрение. Один субъект терпит другого, когда причины против вмешательства превосходят причины в пользу вмешательства. Точно так же Д. Хайд [4] демонстрирует толерантные действия как столкновение перспектив. Один терпит другого, когда игнорируются соображения действий другого и вместо этого происходит концентрация на другом как личности. Таким образом, по мнению Хортона, причины, побуждающие 
людей терпеть других, являются причинами, которые могут превзойти первоначальное неодобрение.

Большое число представителей либеральной философской традиции стремится обосновать терпимость уважением к чужой автономии.

У. Кимлика, например, отмечает, что «либералы исторически рассматривали автономию и терпимость как две стороны одной медали» [5, с. 23].

После письма Дж. Локка «О толерантности» либералы указывали на право других выбирать для себя жизнь, которую они хотят вести. И как основание для такой жизни избирали культурную норму - толерантность. Локк представил ряд аргументов [6, 30] в пользу толерантности. «Ни одно частное лицо не имеет права каким-либо образом наносить ущерб другому лицу в его гражданских наслаждениях, потому что он принадлежит к другой Церкви или Религии. Все права и франшизы, которые принадлежат ему как Человеку или как Денисону, неприкосновенно сохраняются за ним» [6, с. 32]. Долг толерантности требует, чтобы люди уважали индивидуально выбранный путь к религиозному спасению. «Гражданские удовольствия», говорит Локк, «не связаны с религией» $[6$, с. 35$]$.

Р. Диес, обращаясь к религиозной толерантности, утверждает, что в капиталистическом обществе экономический интерес может мотивировать толерантные отношения: «капитализм дает членам различных религиозных групп мотивацию для коммуникации на основе, которая полностью игнорирует религию» [7, с. 147]. Он добавляет: «Если бы люди уделяли больше внимания частным экономическим интересам, они бы меньше обращали внимание на религиозные различия. Вредная озабоченность отдельных людей, скажем, религиозными различиями, могла бы быть смягчена, если бы они осознавали, что выиграют экономически, будучи более толерантными» [7, с. 147]. Толерантность здесь означает желание экономически взаимодействовать с другими, независимо от их идеологических обязательств.

Очевидно, что проблема толерантности находится в центре научных дискуссий. Культивация и практика толерантности - многоаспектные процессы, а интолерантность - это серьезная проблема, влекущая за собой социальную напряженность и эскалацию насилия.

\section{Толерантность в мультикультурном пространстве университета}

В современном обществе формирование толерантности посредством создания мультикультурной среды в стенах высших учебных заведений является как никогда актуальным, поскольку приток иностранных студентов в Россию с каждым годом увеличивается, что приводит к вынужденному совместному проживанию людей, принадлежащих к разным этническим группам и относящимся к различным конфессиям. «Мультикультурная среда сегодня стала для многих стран реальностью, в которой нам следует научиться эффективно взаимодействовать. События, свидетелями которых мы становимся ежедневно, формируют специфическое, не всегда позитивное отношение к проблемам, возникающим у представителей иной культуры в чужой для них иноязычной среде» [8, с. 2674]. Для того чтобы предотвратить распространение нетерпимости, особое внимание стоит уделить университетской среде, в которой происходит формирование личностей нового поколения. В социологии выделяют гендерную, расовую, национальную, религиозную, политическую толерантность. В законе РФ «Об образовании» говорится, что «содержание образования должно содействовать взаимопониманию и сотрудничеству между людьми, народами, независимо от расовой, национальной, этнической, религиозной и социальной принадлежности, учитывать многообразие 
мировоззренческих подходов, способствовать реализации права обучающегося на свободный выбор мнений и убеждений» [9]. Концепция современного человека призывает сделать его толерантным в процессе образования и относиться к этому понятию как культурной ценности.

«В 1995 г. ЮНЕСКО была принята Декларация принципов толерантности включающих уважение, принятие и правильное понимание богатого многообразия культур нашего мира, наших форм самовыражения и способов проявлений человеческой индивидуальности, гармонию в многообразии, направленность на достижение мира и содействие замене культуры войны культурой мира» [10]. Таким образом:

- толерантность - это умение уважать, принимать и ценить то колоссальное разнообразие культур, которое существует в нашем мире;

- толерантность - это активная жизненная позиция, которая основывается на признании всеобщих прав и свобод человека [11].

Идеи глобализации реализуется в материальной форме, часто жесткой, которая имеет как положительные моменты (помощь государств друг другу в решении экономических, экологических, культурных и других проблем), так и отрицательные (отчуждение, выражающееся в терроризме и экстремизме).

Принципы толерантности связаны с новым пониманием рациональных ценностей в культуре. Толерантность в понимании терпимости сегодня является практическим условием выживания человечества и предполагает ряд установок в человеческом сознании, таких как независимость суждений и личную ответственность [12].

Вариант толерантности, который является самым сложным для достижения, - это не просто принятие чужого опыта, но и переосмысление сквозь его призму своего собственного, стремление изменяться, учитывая ценности другого, - полная и абсолютная глобализация, что в принципе недостижимо. Но чем больше подобных элементов будет существовать, тем совершеннее будет общество или принципы его построения. «Современные социальные и экономические условия ставят новые задачи перед университетами. Вузы все больше и больше вовлечены в проблемы современного мира и помогают решать такие проблемы, как подготовка специалистов, образование в социальной элите, а также общее образование. Эти функции начинают определять университетскую жизнь» [13, с. 567].

Для формирования толерантной среды в университетах проводятся различные адаптационные мероприятия. Авторами статьи было проведено исследование, целью которого явилось стремление понять, как адаптационные мероприятия влияют на формирование толерантности у студентов и насколько они толерантны в различных жизненных ситуациях.

В исследовании участвовала группа Российского университета дружбы народов медицинского факультета и 865 студентов-первокурсников Томского политехнического университета, задействованных в программе «Адаптация студентов первого курса к вузовской среде в 2018/19 учебном году».

Как проходит адаптация студентов в университетах, авторы рассмотрели на примере группы РУДН. Это 11 учащихся возрастной группы от 28 до 42 лет. Студенты учат русский язык в течение одного года, далее продолжают обучение по выбранной специальности на русском языке. Пять студентов из Доминиканской республики, четыpe - из Гвинеи, один - из Испании, один - из Коста-Рики. Слушатели из Африки исповедуют ислам, из Южной Америки и Европы - католицизм. Таким образом, ежедневно в течение 10 аудиторных часов студенты из разных стран и культурных традиций нахо- 
дятся в коммуникации, работает с ними преподаватель из России, исповедующий христианство.

В 2018/19 учебном году студенты были интервьюированы по теме «Толерантность как условие существования в мультикультурном мире».

В анкете содержались следующие ситуативные задания и вопросы:

- Всегда ли вы толерантны к представителям разных национальностей? В начале учебного года все студенты отвечают положительно на этот вопрос, но к концу учебного года $50 \%$ респондентов дают отрицательный ответ.

- Любите ли вы разговоры о расовых взаимоотношениях 60 \% респондентов дали положительный ответ.

- При выборе круга общения имеет ли значение цвет кожи человека? 100 \% студентов дали отрицательный ответ.

- Будете ли вы выбирать вторую половину по национальной принадлежности? $97 \%$ респондентов ответили положительно.

- Вы являетесь руководителем. К вам в коллектив трудоустраивается человек, сменивший пол. Ваши подчиненные об этом узнали и пришли к вам с просьбой не брать этого человека. Ваши действия?

- Представьте, что Ваш ребёнок или близкий родственник хочет создать семью с человеком другой национальности (другим цветом кожи, другим вероисповеданием). Как Вы отреагируете? 97 \% респондентов отнесутся отрицательно к такому выбору.

- Представьте, что Ваш ребёнок или близкий родственник решил сменить пол. Как Вы отреагируете? 100 \% респондентов реагируют отрицательно.

- Как вы относитесь к тому, что в классической семье в декретном отпуске будет сидеть мужчина? 100 \% респондентов отрицательно отнеслись к такому решению.

- Пойдете ли вы на религиозный праздник, исповедуя иную веру? 100 \% опрошенных дали положительный ответ.

Таким образом, студенты открыты и толерантны к представителям разных культур, им не важен цвет кожи, но не всегда возможно исключить воспитанное культурой отношение к мужчине и женщине. При вступлении в брак традиции родной культуры будут доминировать над толерантностью. Интолерантно относятся к личностям, сменившим пол, и полностью толерантны к религиозным праздникам разных стран.

Для более глубокого понимания толерантного отношения рассмотрим статус мужчины и женщины и учебный процесс с позиции культурных традиций в родных странах исследуемой группы.

\section{Статус мужчины и женщины}

Африканские студенты: трое мужчин и одна женщина - практикующие врачи. Отвечать на вопрос преподавателя первой женщина не имеет права. Сначала должны ответить мужчины. Учащиеся из Доминиканской республики тоже женского пола. Не зная этой традиции, они не соблюдают её в аудитории. Мужчин из Гвинеи это приводит в замешательство. Более того, если женщина говорит, что он ответил неправильно, у студента ошибка - мужчина-мусульманин не принимает порицания от женщины, даже если она другой веры и другой культуры. Получается, что в данном вопросе гендерных различий для мусульманского мужчины нет возможности проявить толерантность, даже учитывая, что студенты находятся в образовательном пространстве вуза.

\section{Учебный процесс и культурные традиции}


Католики любят отмечать День святого Валентина - любимый праздник почитаемого святого. На занятии студенты приносят всем подарки. Мусульмане проявляют толерантность в отношении праздников, с удовольствием узнают традиции разных стран.

Каждая пятница в исламской традиции священна, поэтому студенты из Конакри просят не ставить занятия на 12 часов дня, т. к. в это время они должны идти в мечеть. Возможно, в будущем руководство университета построит на территории РУДН мечеть, часовню и синагогу, чтобы сделать максимально комфортными проживание и обучение студентов. Пока университет идет не очень охотно на уступки в учебном процессе - все происходит на территории нашей страны, вследствие этого наши правила и традиции приоритетны и студенты стараются соблюдать их тоже. Тем мне менее в корпусах университета есть все необходимое, чтобы совершать намаз, не выходя за пределы. Необходимо подчеркнуть, что для учащихся другого вероисповедания не является удивительным этот процесс в пространстве университета, ведь РУДН является тем вузом, в котором учатся представители 157 стран мира. Каждый год в университете проводится праздник «Вокруг света», где представители всех обучающихся стран показывают свои национальные костюмы, поют песни на родном языке, а посольства стран предоставляют весь наглядный материал, помогающий глубже понять историю и культуру страны. Чем больше мы знаем друг о друге, тем мы более открыты и толерантны.

Подчеркнем еще детали учебного процесса в религиозном контексте. Во время священного месяца Рамадан мусульмане держат пост. Прием воды и пищи совершается только после заката солнца. Студенты приходят на занятия голодные, просят не нагружать их большим количеством информации, т. к. не чувствуют сил для активной работы. Студенты из Европы и Южной Америки не толерантны в этом вопросе. В перерывах между занятиями они употребляют пищу, слушают музыку.

На подготовительном факультете РУДН в обязательной программе есть уроки музыкальной фонетики. На этих занятиях студенты учат русские песни, готовят ежегодные культурные мероприятия к таким праздникам, как Новый год и День Победы. Во время Рамадана учащиеся из Африки не посещают эти занятия, в то время как Южная Америка активно принимает участие во всех внеучебных мероприятиях. Язык является отражением культуры, при изучении русского языка как иностранного видны различия социокультурного контекста. Изучая разные лексические единицы и объединяя их в одно семантическое поле, можно увидеть, что это поле для русского, европейца и американца часто может совпадать, для стран Африки - очень отличаться. Например, для первых кошка и собака - это домашние животные, которых мы можем отнести к теме «Семья», в то время как для людей, исповедующих ислам, кошки и собаки не приближены к человеку. В Коране такие животные являются грязными и удалены от семьи. Также говоря о семье, мусульманин может сказать, что у него четыре жены и восемь детей, Южная Америка и Европа никогда не остаются равнодушными к этим ответам. Возникает большой интерес и много вопросов.

В целом глобальных проблем с адаптацией и толерантным отношением у студентов не возникает. Занятия проходят каждый день, все хорошо понимают, что для успешной реализации учебного процесса необходим порядок, толерантное отношение ко всему иному, аккуратно узнавая драгоценные традиции разных культур, - такое отношение характерно и для студентов РУДН, и для студентов ТПУ.

По окончании программы «Адаптация студентов первого курса к вузовской среде в 2018/19 учебном году» 865 студентов Томского политехнического университета были интервьюированы по теме «Толерантность как условие существования в мультикультурном мире». Авторы провели исследование в данном университете, т. к. была воз- 
можность охватить большой круг студентов. Результаты анкетирования представлены на рисунке.

В результате анализа анкет была вскрыта парадоксальная ситуация, которая заключается в том, что практически все студенты считают себя толерантными в момент лекционных дискуссий, они готовы отстаивать равные права всех и каждого, участвовать в акциях и демонстрациях, проявляя толерантное отношение. Однако в ситуационных заданиях студенты проявили далеко не толерантное отношение.

Студентам для ответа были предложены те же вопросы и ситуации, что в группе РУДН.

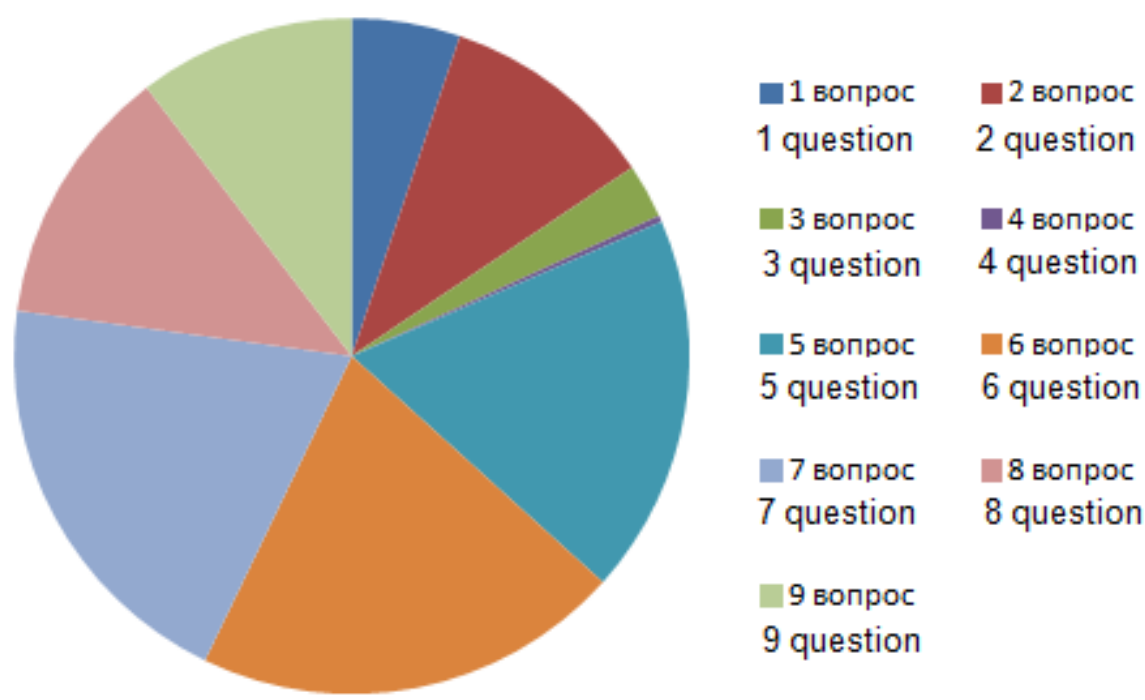

Рисунок. Ответы студентов ТПУ Figure. TPU students answers

Ответы студентов ТПУ в процентном соотношении:

1) $20 \%$ опрошенных дали отрицательный ответ;

2) $40 \%$ студентов ответили отрицательно;

3) $10 \%$ студентов дали отрицательный ответ;

4) $70 \%$ респондентов дали положительный ответ;

5) $79 \%$ респондентов дали отрицательный ответ;

6) $25 \%$ студентов ответили отрицательно;

7) $77 \%$ были против таких изменений;

8) $48 \%$ студентов отнеслись негативно к такому решению;

9) $40 \%$ студентов ответили отрицательно.

Перед тем как написать ответ, некоторые студенты интересовались, будет ли их ответ прочитан и есть ли вероятность, что ответ повлияет на пребывание в университете. Таким образом, участники эксперимента давали часто неискренний ответ. Можно предположить, что толерантное принятие решений и толерантное поведение опрошенных студентов реализуются на низком уровне.

Тем не менее студенты ТПУ в меньшей степени толерантны к представителям разных национальностей, чем студенты РУДН. Они на 20 \% менее склонны к разговорам о расовых взаимоотношениях. Настороженно относятся к людям с другим цветом кожи. Более толерантны к межкультурным бракам. На 18 \% больше желающих принять на работу сотрудника, сменившего пол. Менее традиционны в вопросах мужских и 
женских обязанностей. Не все студенты рады пойти на религиозный праздник другой культуры.

Специфика пребывания иностранных студентов в образовательной среде хорошо изучена как зарубежными, так и российскими авторами. Так, Т. Парсонс [14] выявляет содержание и функциональное значение адаптации как фундаментального свойства социальных систем. Вопросы, связанные со способами приспособительного поведения в условиях социальной аномии, рассматривал Р. Мертон [15]. Э. Гидденс анализирует протекание социальной адаптации в контексте практик повседневного поведения [16]. Российские учёные в основном останавливаются на вопросах, связанных с адаптацией к учебному процессу, в отличие от зарубежных учёных, которые делают акцент на культурной адаптации, обращают внимание на значимость религиозного и культурного факторов в приспособлении к новой среде обитания [17].

Насколько толерантны студенты в процессе вузовской социализации? Можно утверждать, что поведение студентов регламентировано социальными нормами, принятыми в принимающей культуре, а также нормами своей национальной культуры [17]. Студенты более толерантны, если сильно мотивированы к получению профессии, чувствуют ответственность пред семьей и своим государством.

Сегодня парадоксальность в вопросе толерантности заключается в том, что в современном обществе человек обязан быть толерантным, хотя он таковым на самом деле может и не является. Толерантным необходимо быть в социальных сетях. Малейшее проявление интолерантности влечет за собой «дурную славу». Такое двойственное поведение, на наш взгляд, является прямой причиной отчуждения человека, «и однажды появившись, отчуждение проникло во все сферы жизнедеятельности человека: экономическую, политическую, социальную, духовную и так далее. Ни одна сфера жизнедеятельности человека не осталась не затронутой отчуждением. Вся внутренняя человеческая сущность целиком и полностью пронизана отчуждением» [18, с. 28].

Еще в начале XX в. у К. Маркса звучит проблема «отчуждения». Маркс полагал, что процесс социализации индивида в культуре уже содержит в себе формы отчуждения. «Он считал, что отчуждение - процесс социализации, при которой личность начинает ассоциировать свою деятельность в плане коммуникации процессом инородным. Человек становится заложником ситуации-лабиринта с концепцией подавляющего фактора извне» [19].

Сегодня взаимоотношения субъекта и общества в контексте его многочисленных связей еще более формируют отчужденную событийность. Наличие качества толерантности учитывается при приеме на работу, в деловой и публичной коммуникации. Современный человек должен стараться избегать всего, что может ущемить чувства других людей. В современном мире человек, в угоду социальной реальности, вынужден быть не самим собой, а соответствовать ожиданиям общества. Такое положение вещей вызывает когнитивный диссонанс. Постоянное нахождение в таком дуальном состоянии рано или поздно приводит к расстройству психики и деструктивному поведению.

«В последние годы отмечается активизация ряда экстремистских движений, которые вовлекают в свою деятельность молодых людей. Анализ данных за последние пять лет показывает, что возраст четырех из пяти лиц, преступная деятельность которых пресечена, составляет не более 30 лет» [20].

Тогда «в лучшем случае» человек начинает заниматься саморазрушением через социальные пороки (алкоголь, наркоманию), а в худшем - деструкция направляется вовне и приводит такого человека к идее разрушения окружающей действительности, 
начиная с абюзинга в отношениях, заканчивая стремлением глобального уничтожения (терроризм и экстремизм).

Итак, с одной стороны, толерантность делает мир и человека лучше, развивает у человека эмпатию, делает человека гармоничным, с другой - толерантность делает человека отчужденным.

Авторы полагают возможным сформулировать компетенции современного толерантного студента. Иными словами, что необходимо молодым людям, для того чтобы быть более толерантными? Умение избегать конфликтных ситуаций, понимание и принятие других культур и российского социума; преодоление социально-психологического барьера; формирование умений и навыков ведения «диалога культур» с помощью изучения языка; формирование нового социокультурного пространства.

Подводя итог, необходимо ответить на вопрос, почему проблема толерантности в вузах России сегодня стоит не столь остро, как в Западной Европе и особенно в США?

Ответ на данный вопрос имеет два основных аспекта:

1. Культурные традиции России, где одной из важных ценностей является терпимость. Терпимость понимается как непричинение зла другим. Христианская традиция понимает толерантность как милосердие - более понятную и привычную для русских людей добродетель. Любовь к ближнему неразрывно связана с любовью к Богу.

2. Российские вузы заинтересованы в иностранных студентах и используют опыт других стран в организации адаптационных мероприятий для студентов. Например, упомянутая выше программа «Адаптация студентов первого курса к вузовской среде в 2018/19 учебном году».

Авторы статьи полагают, что анализ существующей парадигмы межнациональных отношений и организации межкультурного взаимодействия в российских университетах будет способствовать формированию высокообразованных специалистов, талантливых, творчески одаренных, предприимчивых людей, и поможет нивелировать последствия всех форм отчуждения человека.

\section{СПИСОК ЛИТЕРАТУРЫ}

1. Van Doorn M. The nature of tolerance and the social circumstances in which it emerges // Current Sociology. - 2014. - V. 62. - Iss. 6. - P. 905-927. URL: https://journals.sagepub.com/ doi/abs/10.1177/0011392114537281 (дата обращения 05.02.2020).

2. Нужно завоевывать авторитет: Мария Захарова о роли женщин в дипломатии, трудностях и ценностях // YouTube. URL: https://www.youtube.com/watch?v=WMSAEkHJxbw (дата обращения 10.03.2020).

3. Horton J. Toleration as a virtue // Toleration. An elusive virtue / Ed. by D. Heyd. - Princeton: Princeton University Press, 1996. - P. 28-43.

4. Heyd D. Introduction // Toleration. An elusive virtue / Ed. by D. Heyd. - Princeton: Princeton University Press, 1996. - P. 3-17.

5. Kymlicka W. Milticulturalism: success, failure, and the future. URL: https://www.researchgate. net/publication/268290572_Multiculturalism_Success_Failure_and_the_Future (дата обращения 10.03.2020).

6. Locke J. A letter concerning toleration. URL: https://socialsciences.mcmaster.ca/econ/ugcm/31l3/locke/ toleration.pdf (дата обращения 12.06.2020).

7. Dees R.H. The paradoxical principle and salutary practice: hume on toleration // Hume Studies. - 2005. № 31 (1). - P. 145-164. URL: https://philpapers.org/rec/DEETPP-2 (дата обращения 14.04.2020).

8. Pogukaeva N.V. International students in multicultural environment of innovative university: hermeneutic approach // 11th International Technology, Education and Development Conference (INTED 2017). Proceedings. - Valencia, Spain, 6-8 March, 2017. - Valencia: INTED, 2017. - P. 2674-2680. URL: http://dx.doi.org/10.21125/inted.2017.0735 (дата обращения 14.04.2020). 
9. Об образовании: закон РФ от 10.07 .1992 № 3266-1 (ред. от 12.11.2012). URL: http://www.consultant.ru/document/cons_doc_LAW_1888/ca64c6f50efa15f0d85d1c02a33f605a87298c9f/ (дата обращения 14.04.2020).

10. Декларация принципов терпимости. URL: https:/www.un.org/ru/documents/decl_conv/declarations/ toleranc.shtml (дата обращения 14.06.2020).

11. Осипова С.И., Богданова А.И. Генезис сущности и содержания понятия «толерантность» // Сибирский педагогический журнал. - 2011. - № 6. - С. 114-130.

12. Muldon R., Borgida M. The conditions of tolerance // Politics philosophy \&Economics. - 2012. - № 11 (3). P. 322-344.

13. Education as a condition for social well-being of human / N. Pankova, N. Pogukaeva, M. Korovkin, D. Bolgova // The European Proceedings of Social \& Behavioural Sciences (EpSBS), Lifelong Wellbeing in the World (WELLSO 2016): III International Scientific Symposium. - Tomsk, Russian Federation, 11-16 September 2016. - V. 19. - P. 563-568.

14. Парсонс Т. О структуре социального действия. - М.: Академический проект, 2002. -880 с.

15. Мертон Р. Социальная теория и социальная структура. - М.: АСТ, 2006. - 873 с.

16. Гидденс Э. Устроение общества: очерк теории структурации. - М.: Академический Проект, 2005. $528 \mathrm{c}$.

17. Лондаджим Т. Социокультурная адаптация иностранных студентов, обучающихся в российских вузах: автореф. дис. ... канд. социол. наук. - Нижний Новгород, 2012. - 25 с.

18. Вторушин Н.А., Дергач А.И. Феномен отчуждения личности как философская проблема // Вестник науки Сибири. - 2015. - № 3 (18). - С. 28-37. URL: https://jwt.su/journal/article/view/796 (дата обращения 14.06.2020).

19. Грицанов А.А. Человек и отчуждение // Вопросы социальной теории. - 2010. - Т. IV. - C. 111-128. URL: https://iphras.ru/uplfile/root/biblio/vst/2010/06.pdf (дата обращения 15.03.2020).

20. Особенности профилактики и борьбы с проявлениями экстремизма и терроризма в молодежной среде. URL: https://cao.mos.ru/countering-extremism/features-for-the-prevention-and-suppression-ofmanifestations-of-extremism-and-terrorism-in-the-yout/ (дата обращения 10.02.2020).

Поступила 10.01.2021 2. 
UDC 316.647.5-057.87(470+571)

\title{
TOLERANCE OF STUDENTS AT RUSSIAN UNIVERSITIES AS A CONDITION FOR EXISTENCE AND ALIENATION OF PERSONALITY IN A MULTICULTURAL WORLD
}

\author{
Natalia V. Skakovskaya1, \\ pnv@tpu.ru \\ Nikolai A. Vtorushin 1 , \\ notabene1977@yandex.ru \\ Anna V. Pogukaeva², \\ annapogukaeva1@rambler.ru \\ ${ }^{1}$ National Research Tomsk Polytechnic University, \\ 30, Lenin avenue, Tomsk, 634050, Russia \\ 2 RUDN University, \\ 6, Miklukho-Maklay street, Moscow, 117198, Russia
}

Natalia V. Skakovskaya, Cand. Sc., associate professor, National Research Tomsk Polytechnic University.

Nikolai A. Vtorushin, senior lecturer, National Research Tomsk Polytechnic University.

Anna V. Pogukaeva, senior lecturer, RUDN University.

This paper is analyzing the problem of tolerance essence. In contemporary world there are a lot of changings: on the one hand already known democracy and liberalism, on the other hand new cultural and political reality. The cultural and religious context of toleration is presented. The results of the study of student adaptation in the context of tolerance are comprehended. The relevance of the research is represented by educational transformation: internationalization, computerization and integration of educational systems of different countries. The main aim of the study is to evaluate opportunities and advantages of tolerant behavior in the educational environment. Methods: the core of the research is sociocultural approach; it reveals tendencies of contemporary education. The new aspects of tolerance in the spiritual experience of a person are represented by philosophical reflection. Sociological methods made it possible to analyze the understanding of the tolerant behavior of students. Results. The paper introduces the philosophical assessments of how we can best be tolerant in a variety of cultural societies from the point of view of universal moral values and education. The problem of tolerance is represented in new contexts as a source of personality alienation in numerous cultural communications. The conclusions of the study of the tolerant behavior of students of the Tomsk Polytechnic University and the Moscow University of Friendship of Peoples: the role of religious, cultural, traditional, gender, family aspects in tolerant communication, are presented. The authors have stated the educational competencies of a modern tolerant student: the ability to avoid conflict situations, understanding and acceptance of other cultures, and the Russian society, overcoming the socio-psychological barrier, formation of skills and abilities to conduct a «dialogue of cultures» through language learning, formation of a new socio-cultural space.

Key words: Tolerance, higher education, multiculturalism, student's adaptation, alienation.

\section{REFERENCES}

1. Van Doorn M. The nature of tolerance and the social circumstances in which it emerges. Current Sociology, 2014, vol. 62, Iss. 6, pp. 905-927. Available at: https://jonals.sagepub.com/doi/abs/ 10.1177/0011392114537281 (accessed 5 February 2020). 
2. Nuzhno zavoevyvat avtoritet: Mariya Zakharova o roli zhenshchin v diplomatii, trudnostyakh i tsennostyakh [We need to gain credibility: Maria Zakharova on the role of women in diplomacy, difficulties and values]. YouTube. Available at: https://www.youtube.com/watch?v=WMSAEkHJxbw (accessed 10 March 2020).

3. Horton J. Toleration as a virtue. Toleration. An elusive virtue. Ed. by D. Heyd. Princeton, Princeton University Press, 1996. pp. 28-43.

4. Heyd D. Introduction. Toleration. An Elusive Virtue. Ed. by D. Heyd. Princeton, Princeton University Press, 1996. pp. 3-17.

5. Kymlicka W. Milticulturalism: success, failure, and the future. Available at: https://www.researchgate.net/publication/268290572_Multiculturalism_Success_Failure_and_the_Future (accessed 10 March 2020).

6. Locke J. A letter concerning toleration. Available at: https://socialsciences.mcmaster.ca/econ/ugcm/ 3113/locke/toleration.pdf (accessed 12 June 2020).

7. Dees R.H. The paradoxical principle and salutary practice: hume on toleration. Hume Studies, 2005, no. 31 (1), pp. 145-164. Available at: https://philpapers.org/rec/DEETPP-2 (accessed 14 April 2020).

8. Pogukaeva N.V. International students in multicultural environment of innovative university: hermeneutic approach. $11^{\text {th }}$ International Technology, Education and Development Conference (INTED 2017). Proceedings. Valencia, Spain, 6-8 March, 2017. Valencia, INTED, 2017. pp. 2674-2680. Available at: http://dx.doi.org/10.21125/inted.2017.0735 (accessed 14 April 2020).

9. Ob obrazovanii [On education]. Zakon RF ot 10.07.1992 no. 3266-1 (red. ot 12.11.2012) [Law of the Russian Federation of 10.07.1992 N 3266-1 (as amended on 12.11.2012)]. Available at: http://www.consultant.ru/document/cons_doc_LAW_1888/ca64c6f50efa15f0d85d1c02a33f605a87298c9f/ (accessed 14 April 2020).

10. Deklaratsiya printsipov terpimosti [Declaration of Principles on Tolerance]. Available at: https://www.un.org/ru/documents/decl_conv/declarations/toleranc.shtml (accessed 14 June 2020).

11. Osipova S.I., Bogdanova A.I. Genezis sushchnosti i soderzhaniya ponyatiya «tolerantnost» [Genesis of the essence and content of the concept of «tolerance»]. Sibirskiy pedagogicheskiy zhurnal, 2011, no. 6, pp. 114-130.

12. Muldon R., Borgida M. The conditions of tolerance. Politics philosophy \&Economics, 2012, no. 11 (3), pp. 322-344.

13. Pankova N., Pogukaeva N., Korovkin M., Bolgova D. Education as a condition for social well-being of human. The European Proceedings of Social \& Behavioural Sciences (EpSBS), Lifelong Wellbeing in the World (WELLSO 2016): III International Scientific Symposium. Tomsk, Russian Federation, 11-16 September 2016. Vol. 19, pp. 563-568.

14. Parsons T. O strukture sotsialnogo deystviya [On the structure of social action]. Moscow, Akademicheskiy proekt Publ., 2002. 880 p.

15. Merton R. Sotsialnaya teoriya i sotsialnaya struktura [Social theory and social structure]. Moscow, ACT Publ., 2006. 873 p.

16. Giddens E. Ustroenie obshchestva: ocherk teorii structuratsii [Organization of society: an outline of the theory of structuration]. Moscow, Akademicheskiy Proekt Publ., 2005. 528 p.

17. Londadzhim T. Sotsiokulturnaya adaptatsiya inostrannykh studentov, obuchayushchikhsya $v$ rossiyskih vuzakh. Avtoref. Dis. Kand. nauk [Socio-cultural adaptation of foreign students studying in Russian universities. Cand. Diss. Abstract]. Nizhniy Novgorod, 2012. 25 p.

18. Vtorushin N.A., Dergach A.I. The phenomenon of alienation of the personality as a philosophical problem. Siberian journal of Science, 2015, no. 3 (18), pp. 28-37. In Rus. Available at: https://jwt.su/journal/article/view/796 (accessed 14 June 2020).

19. Gritsianov A.A. Chelovek i otchuzhdenie [Man and alienation]. Voprosy sotsialnoy teorii, 2010, Vol. IV, pp. 111-128. Available at: https://iphras.ru/uplfile/root/biblio/vst/2010/06.pdf (accessed 15 March 2020).

20. Osobennosti profilaktiki $i$ borby s proyavleniyami ekstremizma i terrorizma $v$ molodezhnoy srede [Features of prevention and fight against manifestations of extremism and terrorism in the youth environment]. Available at: https://cao.mos.ru/countering-extremism/features-for-the-prevention-and-suppression-ofmanifestations-of-extremism-and-terrorism-in-the-yout/ (accessed 10 February 2020).

Received: 10 January 2021. 